\title{
А.Г. Пылин
}

\section{ВНЕШНЕТОРГОВОЕ ВЗАИМОАЕЙСТВИЕ ЕАЭС И ВЬЕТНАМА В КОНТЕКСТЕ СОЗААНИЯ ЗОНЫ СВОБОАНОЙ ТОРГОВАИ*}

Аннотация. В статье рассматриваются основные особенности внешнеторгового взаимодействия стран Евразийского экономического союза и Вьетнама в контексте создания между ними зоны свободной торговли. Проводится анализ структуры взаимной торговли, исследуется комплементарность экономик ЕАЭС и Вьетнама, рассматриваются основнье возможности и риски реализации соответствующего соглашения между странами.

Ключевые слова: ЕАЭС, Вьетнам, зона свободной торговли, внешнеторговая открытость, комплементарность и взаимозависимость, торговые эффекть экономической интеграции.

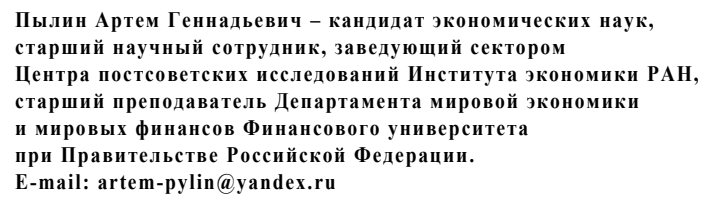

A.G. Pylin. Foreign Trade Cooperation of the Eaeu and Vietnam in the Context of the Free Trade Zone Creation

Abstract. The article studies the main factors of the foreign trade cooperation between the countries of the Eurasian Economic Union (EAEU) and Vietnam in the context of a free trade zone creation, the structure of mutual trade, the compliance of the economies of the EAEU and Vietnam, possible variants and risks of the appropriate agreement implementation between the two countries.

\footnotetext{
* Статья подготовлена при финансовой поддержке РГНФ. Проект «Проблемы имплементации и ожидаемые эффекты Согламения о свободной торговле между Евразийским экономическим союзом и Социалистической Республикой Вьетнам» № 16-27-09001. 
Keywords: EAEU, Vietnam, a free trade zone, foreign trade openness, compliance and interdependence, trade effects of economic integration.

\author{
Pylin Artem Gennadievich - Candidate of Science (Economics), \\ senior research fellow, Head of Sector, Center for post-Soviet Studies \\ of the Institute of Economics of the Russian Academy of Sciences, \\ Senior Lecturer of the Department of World Economy \\ and World Finance, Financial University under the Government \\ of the Russian Federation. E-mail: artem-pylin@yandex.ru
}

\title{
Торговая открытость экономик стран ЕАЭС и Вьетнама
}

В последние десятилетия вовлечение стран в региональные торговые соглашения (РТС) стало одним из основных трендов международной торговли и механизмов интеграции стран в мировую экономику. По данным Всемирной торговой организации (ВТО), на конец 2016 г. в мире насчитывалось 432 действующих РТС, в том числе 241 или более половины $(55,8 \%)$ приходилось на соглашения о зонах свободной торговли и соглашения о присоединении к ним (3СТ) [12]. Созданный в 2015 г. Евразийский экономический союз (ЕАЭС) также стремится активизировать свои внешнеэкономические связи путем заключения ЗСТ с третьими странами. Первым подобным шагом стало заключение Соглашения о свободной торговле между государствами членами ЕАЭС и Социалистической Республикой Вьетнам (СРВ) (ЗСТ ЕАЭС Вьетнам) [3]. Как известно, 29 мая 2015 г. это соглашение было подписано, а 5 октября 2016 г. вступило в силу.

Значимость торговых эффектов от подписания данного соглашения для экономик стран-участниц во многом будет определяться степенью и характером вовлечения этих стран в международную торговлю.

Внешнеторговая открытость - процентное отношение суммы экспорта и импорта товаров и услуг страны к объему ее ВВП - стран ЕАЭС за последние шесть лет имела неравномерную динамику. В 2010-2012 гг. страны региона продолжили после мирового кризиса активно интегрироваться в международные торговые связи, темпы роста их внешней торговли опережали темпы роста экономики (в текущих ценах), а показатели внешнеторговой открытости возрастали. Однако в 2013-2015 гг. произошла стабилизация, а затем и снижение (наиболее сильное в Казахстане и Киргизии) степени вовлеченности стран в мировую торговлю на фоне ухудшения глобальной конъюнктуры. В 2015 г. наибольший уровень внешнеторговой открытости имели Беларусь и Киргизия, а наименьший - Россия (ввиду емкости внутреннего рынка) и Казахстан. При этом по сравнению с близкими по численности 
населения странами Центральной и Восточной Европы государства ЕАЭС заметно уступают по показателю внешнеторговой квоты ${ }^{1}$.

Анализ структуры торговой открытости показывает, что в регионе выделяются страны преимущественно с экспортно ориентированной экономикой (Казахстан и Россия) - чистые экспортеры энергоресурсов, и страны с высокой импортоемкостью экономики (Киргизия и Армения) - чистые импортеры углеводородов. Беларусь одновременно обладает наиболее мощным экспортно ориентированным производством (с максимальной долей экспорта в ВВП) и высокой импортоемкостью, что в значительной степени обусловлено зависимостью ее экспорта от ввоза из-за рубежа сырья и комплектующих.

На фоне государств ЕАЭС сильно выделяется Вьетнам, который существенно превосходит все страны евразийской интеграции по степени вовлеченности в мировую торговлю, которая заметно выросла в последние годы. Структура его торговой открытости весьма сбалансирована - на долю экспорта и импорта приходится примерно по 90\% ВВП. По степени и характеру открытости аналогом Вьетнама в ЕАЭС отчасти можно считать Беларусь, которая, однако, почти в 10 раз уступает ему по емкости внуреннего рынка (численности населения) ${ }^{2}$. В частности, такое сильное отставание стран ЕАЭС во многом обусловлено их более низким уровнем технико-экономического развития и слабым участием в глобальных цепочках добавленной стоимости (ГЦС) по сравнению с Вьетнамом и другими странами ЮгоВосточной Азии.

Динамика вовлеченности стран ЕАЭС и Вьетнама в международную торговлю свидетельствует о расхождении их трендов за последние несколько лет. В 2013-2015 г2. торговая открытость государств евразийской интеграции преимущественно сокращалась, а Вьетнама - возрастала, что в первом случае было обусловлено заметным падением стоимостных объемов внешней торговли, а во втором - их продолжающимся устойчивым ростом. Так, несмотря на ухудшение конъюнктуры на мировых товарных рынках в этот период (ввиду замедления темпов роста глобальной экономики и падения мировых цен на топливно-сырьевые товары), увеличение объемов

1. В 2015 2. внешнеторговая открытость Армении составляла 71\% ВВП, тогда как в Хорватии - 96, Македонии - 113, Словении - 146, Литве-155\%; в Беларуси - 119\%, а в Чехии - 163, Венгрии-171\% (2014); Казахстане - 53\%, тогда как в Румынии - 83; в Киргизии - 115, а в Словакии - 185\% ВВП. По данным World DataBank [11].

2. По данным Всемирного банка (WDI), в 2015 г. численность населения в Беларуси составляла 9,5 млн человек, а во Вьетнаме - 91,7 млн человек. 
вьетнамской внешней торговли определялось ее более высокой товарной и географической диверсификацией по сравнению со странами ЕАЭС ${ }^{3}$.

Схожие тенденции подтверждаются при анализе данных исследования Всемирного экономического форума (ВЭФ), который на основе целого ряда показателей рассчитывает Индекс вовлеченности стран мира в международную торговлю (The Global Enabling Trade Index, GETI). По этому индексу в 2016 г. страны ЕАЭС ухудшили свои позиции в среднем на 10 пунктов по сравнению с 2014 г., заняв 95-е место из 136 стран мира. В то же время Вьетнам значительно улучшил свое положение в этом рейтинге, поднявшись на 14 пунктов и заняв 73-е место, существенно увеличив отрыв от стран ЕАЭС. Единственной в евразийском объединении страной с более высоким, чем у Вьетнама индексом вовлеченности в международную торговлю является Армения (68-е место).

Следует отметить, что Вьетнам опережает страны ЕАЭС по большинству основных показателей открытости экономики. В частности, Россия в рейтинге стран по GETI ухудшила свои позиции на 6 пунктов, заняв лишь 111-е место, отставая от полной интеграции в мировую торговую систему. Вместе с тем выполнение Россией обязательств в рамках членства в ВТО, снижение применяемой ставки тарифа с 9,5 до 5,8\% способствовали улучшению доступности ее внутреннего рынка. Но уровень его открытости по-прежнему остается низким из-за сложности тарифов и низкой доли беспошлинного импорта - лишь 39,7\%. При этом доступность внешних рынков для РФ также остается на низком уровне ввиду относительно высокого среднего уровня тарифа $-5,0 \%$, применяемого к российским товарам. По оценкам ВЭФ, на слабую вовлеченность России в глобальную торговлю также влияет низкая эффективность администрирования на границах. Несмотря на хорошо развитую инфраструктуру (37-е место), транспортные услуги являются неэффективными (82-е место), что делает поставки весьма сложными и недоступными (109-е место). Кроме того, частный сектор страдает от неопределенной защиты прав собственности (119-е место) и низкой доступности финансов (112-е место), что негативно влияет на деловой климат в стране (113-е место) [7, c. 258-259].

Значительное улучшение позиций Вьетнама во многом было обусловлено повышением эффективности управления на границах и увеличением доли беспошлинно ввозимых товаров - до 70,9\% (65-е место) против 55,2\% два года назад. При этом средний импортный тариф был повышен с 6,8 до 7,9\% (91-е место). Возможности Вьетнама выходить на внешние рынки также

3. В 2013-2015 г2. общий товарооборот Вьетнама вырос на 43,6\% и достиг 328 млрд долл., а стран ЕАЭС-5 - сократился на 38,6\% и составил 670 млрд долл. Pасчеты автора по данным ITC. Trade Map, January 2017. 
улучшились, благодаря снижению применяемого к вьетнамским товарам среднего тарифа - с 4,5 до 3,3\% (28-е место). В то же время произошло заметное улучшение транспортной инфраструктуры и бизнес-среды [7, с. 314-315].

\section{Структура взаимной торговли ЕАЭС и Вьетнама}

В 2010-2015 гг. динамика торгового взаимодействия стран ЕАЭС и Вьетнама носила неравномерный характер: вплоть до 2013 г. включительно отмечался рост стоимостных объемов их экспортно-импортных операций, а после - последовал спад. При этом более существенным оказалось падение экспорта из стран «евразийской пятерки» (более чем на $1 / 3$ ), чем спад встречного импорта из Вьетнама (лишь на $1 / 5$ ), что во многом объясняется ухудшением конъюнктуры на мировых товарных рынках и спецификой товарной структуры взаимной торговли.

В настоящее время ЕАЭС и Вьетнам не являются друг для друга крупнейшими торговыми партнерами. В 2015 г. доля СРВ во внешней торговле стран ЕАЭС составляла лишь $0,5 \%$, а доля «евразийской пятерки» в товарообороте Вьетнама - 0,8\% [6]. Однако за рассматриваемый период доля Вьетнама во внешней торговле ЕАЭС немного увеличилась - прежде всего за счет опережающего роста вьетнамского экспорта в Казахстан и Россию. Так, в 2010-2015 гг. ввоз товаров в Казахстан из СРВ вырос в 7,1 раза - до 196 млн долл., а в РФ почти в 2 раза - до 2,1 млрд долл. Все страны ЕАЭС (за исключением Беларуси) имеют устойчивое отрицательное сальдо в торговле с Вьетнамом, которое в 2015 г. в России составляло 1,2 млрд долл., в Казахстане - 185 млн долл. В то же время в Беларуси профицит торговли с СРВ составлял 72 млн долл. [6].

С учетом географических особенностей евразийского пространства и масштабов экономик стран - участниц ЕАЭС относительно значимой внешняя торговля с Вьетнамом представляется для России, Казахстана и отчасти Беларуси, хотя его доля в этих странах практически не превышает $1 \%$ (табл. 1). При этом на Россию приходится почти 90\% всей торговли ЕАЭС с Вьетнамом, а на Казахстан и Беларусь - по 5-6\%.

Низкие абсолютные и относительные показатели взаимной торговли стран ЕАЭС и СРВ обусловлены слабым разнообразием ее товарной структуры, особенно экспорта из стран евразийского объединения (табл. 2). Крайне низкий уровень товарной диверсификации объясняет неустойчивость объемов экспорта стран ЕАЭС во Вьетнам, основу которых составляют топливносырьевые товары. Так, основу белорусского экспорта в СРВ составляют лишь несколько позиций - калийные удобрения, на которые приходится свыше $3 / 4$ всего вывоза, а также транспортные средства для перевозки грузов $(8,6 \%)$, поршневые двигатели внутреннего сгорания $(3,6)$ и полиамиды $(2,5)$, тогда 
как на все прочие товары - чуть более $8 \%$. Основу экспорта Казахстана во Вьетнам составляют необработанный свинец $(83,7 \%)$ и асбест $(9,2 \%)$. Сравнительно более диверсифицированную структуру экспорта во Вьетнам имеет Россия - во многом за счет военно-технического сотрудничества двух стран. Основу российского экспорта в СРВ составляют оружие и боеприпасы, радиолокационная аппаратура, нефть и нефтепродукты, калийные удобрения, каменный уголь и сырая нефть, на которые в совокупности приходится почти $2 / 3$ экспорта страны в СРВ [6].

Таблица 1

УАЕАЬНЫЙ ВЕС ВЬЕТНАМА

ВО ВНЕШНЕЙ ТОРГОВАЕ СТРАН - ЧАЕНОВ ЕАЭС, \%

\begin{tabular}{|l|l|l|l|}
\hline \multicolumn{2}{|c|}{ Страны } & 2010 & 2015 \\
\hline \multirow{2}{*}{ Армения } & экспорт & 0,03 & 0,01 \\
\cline { 2 - 4 } & импорт & 0,26 & 0,46 \\
\hline \multirow{2}{*}{ Беларусь } & экспорт & 0,42 & 0,41 \\
\cline { 2 - 4 } & импорт & 0,12 & 0,13 \\
\hline \multirow{2}{*}{ Казахстан } & экспорт & 0,02 & 0,02 \\
\cline { 2 - 4 } & импорт & 0,11 & 0,64 \\
\hline \multirow{2}{*}{ Кыргызстан } & экспорт & 0,00 & 0,10 \\
\cline { 2 - 4 } & импорт & 0,11 & 0,09 \\
\hline \multirow{2}{*}{ Россия } & экспорт & 0,28 & 0,24 \\
\cline { 2 - 4 } & импорт & 0,49 & 1,12 \\
\hline \multirow{2}{*}{ ЕАЭС-5 } & экспорт & 0,26 & 0,23 \\
\cline { 2 - 4 } & импорт & 0,40 & 0,92 \\
\hline
\end{tabular}

Источник: Расчеты автора по данным [6].

Таблица 2

ТОВАРНАЯ СТРУКТУРА ЭКСПОРТА СТРАН ЕАЭС-З

BO BЬETHAM, \%

\begin{tabular}{|l|c|c|c|c|c|c|}
\hline \multirow{2}{*}{ Товарные группь } & \multicolumn{2}{|c|}{ Беларусь } & \multicolumn{2}{|c|}{ Казахстан } & \multicolumn{2}{c|}{ Россия } \\
\cline { 2 - 8 } & 2010 & 2015 & 2010 & 2015 & 2010 & 2015 \\
\hline Все товары & 100,0 & 100,0 & 100,0 & 100,0 & 100,0 & 100,0 \\
\hline Продовольственные товары и с/х сырье & 0,2 & 0,9 & 0,0 & 0,0 & 1,1 & 2,4 \\
\hline Минеральные продукты & 0,0 & 0,0 & 8,5 & 9,2 & 11,1 & 28,1 \\
\hline $\begin{array}{l}\text { Продукция химической промышленно- } \\
\text { сти }\end{array}$ & 51,5 & 82,0 & 0,0 & 0,2 & 6,6 & 15,5 \\
\hline $\begin{array}{l}\text { Древесина и целлюлозно-бумажные } \\
\text { изделия }\end{array}$ & 0,1 & 0,1 & 0,0 & 0,0 & 1,3 & 2,9 \\
\hline Текстиль, текстильные изделия и обувь & 0,2 & 0,0 & 0,0 & 0,0 & 0,1 & 0,3 \\
\hline Металлы и изделия из них & 2,0 & 0,0 & 91,5 & 84,3 & 39,6 & 3,8 \\
\hline $\begin{array}{l}\text { Машины, оборудование и транспортные } \\
\text { средства }\end{array}$ & 22,3 & 16,9 & 0,1 & 5,7 & 32,4 & 28,2 \\
\hline Прочее & 23,7 & 0,1 & 0,0 & 0,6 & 7,8 & 18,8 \\
\hline
\end{tabular}

Источник: Расчеты автора по данным [6]. 
Товарная структура импорта стран ЕАЭС из Вьетнама более диверсифицирована, что во многом определяет сравнительную устойчивость объемов ввоза вьетнамских товаров. Основу импорта трех ключевых стран евразийского объединения (ЕАЭС-3) из СРВ составляют машины, оборудование и транспортные средства, текстиль, текстильные изделия и обувь, а также продовольственные товары (табл. 3). Так, в импорте России из Вьетнама преобладают мобильные телефоны, процессоры и контроллеры, вычислительные цифровые портативные машины (компьютеры), кофе, обувь, пылесосы, куртки и ветровки, орехи кешью, черный чай, креветки, дорожные сумки и печатные машины, на которые в совокупности приходится почти $3 / 4$ всего ввоза из СРВ в РФ [6].

ТОВАРНАЯ СТРУКТУРА ИМПОРТА СТРАН ЕАЭС-З

Таблица 3

И3 BЬETHAMA, \%

\begin{tabular}{|c|c|c|c|c|c|c|}
\hline \multirow{2}{*}{ Товарные группь } & \multicolumn{2}{|c|}{ Беларусь } & \multicolumn{2}{|c|}{ Казахстан } & \multicolumn{2}{|c|}{ Россия } \\
\hline & 2010 & 2015 & 2010 & 2015 & 2010 & 2015 \\
\hline Все товары & 100,0 & 100,0 & 100,0 & 100,0 & 100,0 & 100,0 \\
\hline $\begin{array}{l}\text { Продовольственные товары и } \mathrm{c} / \mathrm{x} \\
\text { сырье }\end{array}$ & 52,2 & 39,7 & 38,7 & 4,1 & 26,8 & 16,4 \\
\hline Минеральные продукты & 0,0 & 0,2 & 0,0 & 0,1 & 0,2 & 0,4 \\
\hline $\begin{array}{l}\text { Продукция химической промыш- } \\
\text { ленности }\end{array}$ & 4,8 & 6,2 & 3,8 & 1,4 & 6,2 & 2,0 \\
\hline $\begin{array}{l}\text { Древесина и целлюлозно-бумажные } \\
\text { изделия }\end{array}$ & 0,1 & 0,3 & 2,1 & 0,0 & 0,5 & 0,2 \\
\hline $\begin{array}{l}\text { Текстиль, текстильные изделия и } \\
\text { обувь }\end{array}$ & 9,6 & 12,5 & 23,9 & 6,9 & 21,5 & 21,5 \\
\hline Металлы и изделия из них & 0,5 & 3,7 & 0,9 & 0,4 & 0,6 & 1,1 \\
\hline $\begin{array}{l}\text { Машины, оборудование и транс- } \\
\text { портные средства }\end{array}$ & 31,6 & 35,3 & 29,4 & 85,2 & 41,2 & 54,7 \\
\hline Прочее & 1,2 & 2,1 & 1,2 & 1,9 & 3,0 & 3,7 \\
\hline
\end{tabular}

Источник: Расчеты автора по данным [6].

Значительное преобладание разнообразных машин и оборудования (прежде всего, мобильных телефонов, компьютеров, офисной и бытовой техники) во вьетнамском экспорте в Россию во многом обусловлено деятельностью крупных японских, южно-корейских, американских и европейских ТНК, которые осуществляют во Вьетнаме сборку данной техники. В сфере производства электроники и электротехники здесь лидируют вьетнамские подразделения таких крупных компаний, как Samsung Electronics (Республика Корея), Intel (США), Panasonic (Япония), Canon (Япония), Sony (Япония), LG Electronics (Республика Корея), GE (США), Siemens (Германия), Cisco 
(США) и Electrolux (Швеция) [10, 9]. Крупные ТНК представлены в секторе производства текстиля и одежды (например, Nike и Adidas), а также в пищевой промышленности (Unilever, Cargill, Nestlé и PepsiCo). Отметим, что среди факторов притока прямых иностранных инвестиций (ПИИ) и открытия подразделений крупных ТНК во Вьетнаме выделяются выгодное транспортногеографическое положение страны, сравнительно емкий внутренний рынок, участие СРВ в АСЕАН и других РТC [4, с. 14-20], а также дешевая рабочая сила.

\section{О торговой компмементарности ЕАЭС и СРВ}

Потенциальные торговые эффекты от экономической интеграции стран также во многом определяются уровнем их взаимодополняемости, для чего в научной литературе применяется индекс торговой комплементарности ${ }^{4}$. Как известно, две страны с более высоким индексом комплементарности при прочих равных условиях могут в большей степени выиграть от углубления торгового взаимодействия после заключения преференциального торгового соглашения. Однако при этом необходимо учитывать расстояние между странами и транспортные издержки, а также размеры их экономик.

Анализ данных индекса комплементарности между странами ЕАЭС и Вьетнамом (табл. 4) позволяет выделить три группы пар стран:

1. С относительно высоким индексом $(0,4)$, среди которых четыре пары стран: Вьетнам - Казахстан, Вьетнам - Россия, Беларусь - Вьетнам и Вьетнам Беларусь. Именно в этой группе имеется наибольший потенциал для активизации торгового взаимодействия.

4. Индекс торговой комплементарности показывает, насколько экспортный профиль одной страны соответствует импортному профилю другой.

Индекс торговой комплементарности между странами $k u j$ определяется следующим образом:

$$
S e_{j} m_{k}=1-\frac{\sum_{i}\left|E_{i j}-M_{i k}\right|}{2},
$$

где Sejmk - индекс торговой комплементарности между экспортером ј и импортером $k$, $i$ - товары с трехзначным кодом MCTK (SITC Rev. 3), j- экспортер (страна или группа стран), $k$-импортер (страна или группа стран), Еij-доля товара $і$ в общем экспорте страны $j$, Міk - доля товара і в общем импорте страны $k$.

Значение индекса равняется 0 в том случае, если одна страна не импортирует ни одного вида товара, экспортируемого другой страной; значение индекса равно 1 в том случае, если доли экспорта и импорта в этих странах в точности совпадают. 
РОССИЯ И МИР В ХХІ ВЕКЕ

2. Со средним уровнем комплементарности $(0,3)$, куда вошли также четыре пары стран: Кыргызстан - Вьетнам, Вьетнам - Кыргызстан, Вьетнам Армения и Россия - Вьетнам. Эти пары стран имеют средние возможности наращивания взаимных торговых связей.

3. С относительно низким индексом $(0,1)$, которую образуют только две пары - Армения - Вьетнам и Казахстан - Вьетнам с наименьшим потенциалом увеличения торгового взаимодействия.

\section{АИНАМИКА ИНАЕКСА ТОРГОВОЙ КОМПАЕМЕНТАРНОСТИ}

Таблица 4

\section{СТРАН ЕАЭС И ВЬETHАMА}

\begin{tabular}{|l|c|c|c|c|c|}
\hline Экспортер-импортер & 2000 & 2005 & 2010 & 2013 & $2010-2013$ \\
\hline Вьетнам - Казахстан & 0,250 & 0,304 & 0,384 & 0,430 & 0,410 \\
\hline Вьетнам - Россия & 0,296 & 0,300 & 0,389 & 0,389 & 0,386 \\
\hline Беларусь - Вьетнам & 0,503 & 0,432 & 0,389 & 0,400 & 0,375 \\
\hline Вьетнам - Беларусь & 0,386 & 0,420 & 0,334 & 0,364 & 0,342 \\
\hline Кыргызстан - Вьетнам & 0,155 & 0,255 & 0,297 & 0,343 & 0,328 \\
\hline Вьетнам - Кыргызстан & 0,186 & 0,197 & 0,305 & 0,309 & 0,309 \\
\hline Вьетнам - Армения & 0,214 & 0,210 & 0,309 & 0,292 & 0,305 \\
\hline Россия - Вьетнам & 0,354 & 0,361 & 0,265 & 0,304 & 0,280 \\
\hline Армения - Вьетнам & 0,148 & 0,126 & 0,151 & 0,119 & 0,148 \\
\hline Казахстан - Вьетнам & 0,122 & 0,149 & 0,150 & 0,149 & 0,145 \\
\hline
\end{tabular}

Источник: Составлено и рассчитано по данным [8].

Таким образом, в среднесрочной перспективе при реализации ЗСТ ЕАЭС Вьетнам существует значительный потенциал для увеличения вьетнамского экспорта в Казахстан и Россию (который отчасти уже реализуется), а также в Беларусь. Вместе с тем сохраняются значительные возможности для роста белорусского экспорта во Вьетнам, но для этого необходимо будет улучшить транспортную доступность и логистику между двумя странами. В то же время возможности существенно нарастить армянский и казахстанский экспорт во Вьетнам будут крайне ограничены ввиду низкого соответствия их нынешнего экспортного профиля импортному профилю СРВ.

\section{Возможности и риски торгового взаимодействия}

Значимость создаваемой зоны свободной торговли между странами Евразийского экономического союза и СРВ определяетя тем, что это первый подобный проект для ЕАЭС, а потому крайне важен его позитивный, демонстрационный эффект, в том числе и других стран, которые в настоящее время ведут переговоры по заключению аналогичного соглашения с евразийской 
пятеркой (Египет, Таиланд, Иран и др.). При этом для самих стран ЕАЭС с учетом сравнительно низкой доли взаимной торговли также важно последовательно идти по пути заключения РТС с третьими странами. Развитие тесных торгово-экономических связей ЕАЭС с Вьетнамом и другими странами позволит сократить высокую зависимость данного интеграционного объединения от таких крупных партнеров, как ЕС и КНР.

Реализация положений ЗСТ ЕАЭС - Вьетнам позволит странам-участницам получить преференциальный доступ на весьма емкие рынки друг друга: для СРВ открывается общий евразийский рынок с населением в 183 млн человек, для стран Евразийского экономического союза - вьетнамский рынок с населением около 92 млн человек, а с учетом участия этой страны в АСЕАН свыше 592 млн человек. Как известно, в соглашении речь идет прежде всего о взаимной отмене таможенных пошлин. По данным Евразийской экономической комиссии (ЕЭК), отмена ввозных таможенных пошлин вьетнамской стороной не охватывает только $12 \%$ товарной номенклатуры, по большинству из которых у стран ЕАЭС отсутствует экспортный интерес. Причем соглашение обязывает Вьетнам отменить для поставщиков из государствчленов ввозные таможенные пошлины более чем на $59 \%$ позиций сразу же, а в отношении еще $29 \%$ ставки ввозных таможенных пошлин будут аннулированы в течение переходных периодов, которые составляют от пяти до десяти лет.

Согласно соглашению, Вьетнам открывает рынок для многих товаров стран ЕАЭС:

- сельскохозяйственный сектор: говядина, свинина и птица, мясная переработанная продукция, консервированная рыба, семена, мука, молочная продукция, сыр, растительное масло, корма для животных, алкогольная продукция;

- промышленный сектор: драгоценные камни, шины, асбест, трубы, прокат, корабли, механическое оборудование, электронное оборудование, детали для автомобилей, изделия из стали, сельхозтехника, автобусы, легковые автомобили, грузовики, нефтепродукты [1].

В силу того, что соглашение о зоне свободной торговли между ЕАЭС и СРВ вступило в силу лишь 5 октября 2016 г., подводить даже предварительные итоги его реализации для стран-участниц преждевременно. Отметим лишь, что по итогам 2016 г. товарооборот России с Вьетнамом остался практически на уровне предыдущего года и составил 3,8 млрд долл. $(0,8 \%$ от всей внешней торговли РФ). В то же время российский экспорт в СРВ сократился на $1 / 4$ и составил менее 1,4 млрд долл., а встречный импорт увеличился на $1 / 5$ 
и достиг почти 2,5 млрд долл. ${ }^{5}$, что уже свидетельствует о весьма существенном наращивании поставок вьетнамских товаров на российский рынок даже в условиях его стагнации.

Соглашение потенциально создает условия для роста и диверсификации взаимной торговли между ЕАЭС и Вьетнамом, а также предусматривает защитные механизмы против недобросовестной конкуренции и неконтролируемого наращивания импорта. Кроме того, открытие СРВ и выход на рынки динамично развивающихся стран АСЕАН может стать одним из драйверов роста экономики в евразийских странах.

Однако при реализации данного соглашения необходимо учитывать возможные риски и ограничения. Одним из таких рисков может стать быстрое наращивание экспорта Вьетнама в страны ЕАЭС с учетом весьма высокой конкурентоспособности вьетнамских товаров, производящихся в том числе с использованием технологий ведущих развитых стран. Странам евразийской интеграции будет достаточно сложно закрепиться на вьетнамском рынке, где работают подразделения крупнейших ТНК. Важно также учитывать сравнительно высокую транспортную удаленность стран ЕАЭС и СРВ.

В связи с этим для увеличения объемов взаимной торговли и ее диверсификации необходимо наращивать взаимные инвестиции, создавать совместные предприятия и общими усилиями встраиваться в цепочки добавленной стоимости. Отметим, что сохраняется значительный потенциал в создании глобальных цепочек стоимости между Россией и странами АСЕАН [2, с. 6476]. Эффективное использование открывающихся в рамках соглашения ЗСТ ЕАЭС - СРВ возможностей и учет некоторых рисков и ограничений может привести к получению позитивных интеграционных эффектов для обеих сторон уже в среднесрочной перспективе.

\section{Библиография}

1. Вступило в силу соглашение о зоне свободной торговли между Евразийским экономическим союзом и Вьетнамом // ЕЭК - Европейская экономическая комиссия. 2016. 06 октября. URL: http://www.eurasiancommission.org/ru/nae/news/Pages/06-10-2016-1.aspx (Дата обращения: 15.01.2017.)

2. Мурадов К. Россия и АСЕАН в глобальных производственных цепочках // Международная жизнь. 2016. № 5. С. 64-76.

3. Соглашение о свободной торговле между Евразийским экономическим союзом и его государствами-членами, с одной стороны, и Социалистической Республикой Вьетнам -

5. Расчеты автора по данным [5]. Отметим, что показатели объема экспорта России во Вьетнам в 2014-2015 ге. в базах данных ITC. Trade Мар и ФТС РФ заметно отличались. Согласно данным [6], российский экспорт в СРВ составлял в этот период 644,5 млн долл. и 824,4 млн долл. соответственно, а по данным ФТС РФ1451,7 млн долл. и 1842,5 млн долл. 
с другой // ЕЭК - Европейская экономическая комиссия. URL: http://www.eurasiancommission.org/ru/act/trade/dotp/sogl_torg/Documents/EAEU-VN\%20FTA_rus.pdf (Дата обращения: 12.01.2017.)

4. Тригубенко М.Е. Развитие внешней торговли Вьетнама в новой архитектонике глобальных экономических отношений в XXI веке // Экономика и управление. 2016. № 5 (127).

5. Федеральная таможенная служба: Официальный сайт // URL: http://www.customs.ru/ (Дата обращения: 15.01.2017).

6. ITC. Trade Map. 2017. January // URL: http://www.trademap.org/Index.aspx (Дата обращения: 15.01 .2017$.

7. The Global Enabling Trade Report 2016 // World Economic Forum. Geneva, 2016.

8. UNCTAD // URL: http://unctadstat.unctad.org/wds/ReportFolders/reportFolders.aspx (Дата обращения: 17.01.2017.)

9. Vietnam Best Places to Work 2014 survey results released // Vietnam Investment Review. 2015.05.03. URL: http://www.vir.com.vn/vietnam-best-places-to-work-2014-survey-results-released. html (Дата обращения: 15.01.2017.)

10. Vietnam. Top 200 Companies // Business-in-Asia. URL: http://www.business-in-asia. net/?s=+Top+200+Companies (Дата обращения: 15.01.2017.)

11. World Development Indicators // World DataBank. 2017. January. URL: http://databank. worldbank.org/data/reports.aspx?source=world-development-indicators (Дата обращения: 15.01.2017.)

12. WTO. Regional Trade Agreements Information System (RTA-IS) // URL: http://rtais. wto.org/UI/publicsummarytable.aspx (Дата обращения: 05.01.2017.)

\section{References}

Federal'naja tamozhennaja sluzhba: Oficial'nyj sajt // URL: http://www.customs.ru/ (Data obrashhenija: 15.01.2017.)

ITC. Trade Map. 2017. January // URL: http://www.trademap.org/Index.aspx (Data obrashhenija: 15.01.2017.)

Muradov K. Rossija i ASEAN v global'nyh proizvodstvennyh cepochkah // Mezhdunarodnaja zhizn'. 2016. N 5. S. 64-76.

Soglashenie o svobodnoj torgovle mezhdu Evrazijskim jekonomicheskim sojuzom i ego gosudarstvami - chlenami, s odnoj storony, i Socialisticheskoj Respublikoj V'etnam, s drugoj storony // EEC - Eurasian economic commission. URL: http://www.eurasiancommission.org/ru/act/trade/dotp/ sogl_torg/Documents/EAEU-VN\%20FTA_rus.pdf (Data obrashhenija: 12.01.2017.)

The Global Enabling Trade Report 2016 // World Economic Forum. Geneva, 2016.

Trigubenko M.E. Razvitie vneshnej torgovli V'etnama v novoj arhitektonike global'nyh jekonomicheskih otnoshenij v XXI veke // Jekonomika i upravlenie. 2016. N 5 (127).

UNCTAD // URL: http://unctadstat.unctad.org/wds/ReportFolders/reportFolders.aspx (Data obrashhenija: 17.01.2017.)

Vietnam Best Places to Work 2014 survey results released // Vietnam Investment Review. 2015.05.03. URL: http://www.vir.com.vn/vietnam-best-places-to-work-2014-survey-results-released. html (Data obrashhenija: 15.01.2017.)

Vietnam. Top 200 Companies // Business-in-Asia. URL: http://www.business-in-asia. net/?s=+Top+200+Companies (Data obrashhenija: 15.01.2017.)

Vstupilo v silu soglashenie o zone svobodnoj torgovli mezhdu Evrazijskim jekonomicheskim sojuzom i V'etnamom // EEC - Eurasian economic commission. 2016. 06 oktjabrja. URL: 


\section{РОССИЯ И МИР В ХХІ ВЕКЕ}

http://www.eurasiancommission.org/ru/nae/news/Pages/06-10-2016-1.aspx (Data obrashhenija: 15.01.2017.)

World Development Indicators // World DataBank. 2017. January. URL: http:// databank.worldbank.org/data/reports.aspx?source=world-development-indicators (Data obrashhenija: 15.01.2017.)

WTO. Regional Trade Agreements Information System (RTA-IS) // URL: http://rtais. wto.org/UI/publicsummarytable.aspx (Data obrashhenija: 05.01.2017.) 